\title{
Carbon-13 cross-polarization magic-angle spinning nuclear magnetic resonance (CPMAS NMR) for measuring proanthocyanidin content and procyanidin to prodelphinidin ratio in sainfoin (Onobrychis viciifolia) tissues
}

Article

Accepted Version

Fryganas, C., Drake, C., Ropiak, H. M., Mora Ortiz, M., Smith, L. M. J., Mueller-Harvey, I. and Kowalczyk, R. (2018) Carbon13 cross-polarization magic-angle spinning nuclear magnetic resonance (CPMAS NMR) for measuring proanthocyanidin content and procyanidin to prodelphinidin ratio in sainfoin (Onobrychis viciifolia) tissues. Journal of Agricultural and Food Chemistry, 66 (16). pp. 4073-4081. ISSN 0021-8561 doi: https://doi.org/10.1021/acs.jafc.8b01215 Available at https://centaur.reading.ac.uk/76550/

It is advisable to refer to the publisher's version if you intend to cite from the work. See Guidance on citing.

To link to this article DOI: http://dx.doi.org/10.1021/acs.jafc.8b01215

Publisher: American Chemical Society 
All outputs in CentAUR are protected by Intellectual Property Rights law, including copyright law. Copyright and IPR is retained by the creators or other copyright holders. Terms and conditions for use of this material are defined in the End User Agreement.

\section{www.reading.ac.uk/centaur}

\section{CentAUR}

Central Archive at the University of Reading

Reading's research outputs online 


\section{Carbon-13 Cross-Polarization Magic-Angle Spinning}

2 Nuclear Magnetic Resonance (CPMAS NMR) for

3 Measuring Proanthocyanidin Content and Procyanidin to

\section{Prodelphinidin Ratio in Sainfoin (Onobrychis viciifolia)}

5 Tissues

7 Christos Fryganas, ${ }^{\dagger},{ }^{\star}{ }^{*}$ Christopher Drake, ${ }^{\dagger}$ Honorata M. Ropiak, ${ }^{\dagger}, \S$ Marina Mora-Ortiz, ${ }^{\#}$

8 Lydia M. J. Smith, ${ }^{\perp}$ Irene Mueller- Harvey, ${ }^{\dagger}$ and Radoslaw M. Kowalczyk,, , *

$10 \dagger$ School of Agriculture, Policy and Development, University of Reading, P.O. Box 236, 1

11 Earley Gate, Reading RG6 6AT, United Kingdom

$12{ }^{\#}$ Department of Food and Nutritional Sciences, University of Reading, Whiteknights

13 Campus, P.O. Box 226, Reading RG6 6AP, United Kingdom

$14{ }^{\perp}$ National Institute of Agricultural Botany, Huntingdon Road, Cambridge CB3 OLE, United

15 Kingdom

16 "Chemical Analysis Facility, School of Chemistry, Food and Pharmacy, University of

17 Reading, P.O. Box 224, Whiteknights Campus, Reading RG6 6AD, United Kingdom

${ }^{*}$ Corresponding author (Tel.: + 44 (0)118 378 4756; Email: r.m.kowalczyk@,reading.ac.uk)

$\$$ CF Present address: Biobased Chemistry \& Technology, Wageningen University, P.O. Box 17, 6700 AA, Bornse Weilanden 9, Wageningen, The Netherlands

$\S$ HMR Present address: Pirbright Institute, Ash Road, Pirbright, Woking GU24 0NF, United Kingdom 


\section{ABSTRACT}

22 A procedure based on ${ }^{13} \mathrm{C}$ CPMAS NMR was developed to study procyanidins (PCs) and 23 prodelphinidins (PDs) directly in milled sainfoin plant tissues. Blackcurrant and Tilia samples enabled reference spectra of purified proanthocyanidin (PA) fractions, crude extracts and milled plant tissues, with characteristic resonances at 155, 144 and $132 \mathrm{ppm}$. PC/PD ratios were estimated from the $\mathrm{I}_{132} / \mathrm{I}_{155}$ intensity ratio and differed by 2.5 to $5.9 \%$ compared to thiolysis data. Normalization to the $155 \mathrm{ppm}$ signal intensity from reference spectra enabled analysis of PA contents with an error of ca $8 \mathrm{~g}$ PAs/100 g plant tissue. The procedure estimates the lignin contribution and allows for a correction of the PA content. In six sainfoin accessions, estimated PA contents, were 1.6- to 20.8-fold higher than the thiolysis and 1.4- to 2.6-fold higher than the HCl-butanol-acetone results. Method differences may reflect the presence of unextractable, possibly high molecular weight PAs in sainfoin.

KEYWORDS: condensed tannins; CPMAS NMR; thiolysis; HCl-butanol-acetone assay; extractable and non-extractable proanthocyanidins; sainfoin; 


\section{INTRODUCTION}

47 Given the beneficial effects of proanthocyanidins (PAs) on human and animal

48 nutrition and health, ${ }^{1,2}$ there is a need for analytical methods capable of providing

49 information on the true PA content and their composition in plants. However, their analysis is

50 challenging as many plants synthesize complex polymeric mixtures of PAs (Figure 1). ${ }^{3,4}$

51 Extractable PAs are typically analyzed after degradation in the presence of nucleophiles

52 followed by chromatographic separation of the reaction products and mass spectrometric

53 analysis; this gives data on PA content, flavan-3-ol subunit composition, mean degree of

54 polymerization (mDP) and procyanidin/prodelphinidin (PC/PD) and cis/trans flavan-3-ol

55 ratios. ${ }^{5-8}$ Extraction, however, is often incomplete as many plants also contain large quantities

56 of unextractable PAs, which can lead to underestimation of total contents. ${ }^{9-11}$ Therefore, in

57 planta PA depolymerization with HCl-butanol-acetone, thiolysis or phloroglucinolysis has

58 been used to estimate extractable plus unextractable PAs; but, incomplete reaction, side

59 reactions or degradation-resistant PAs continue to pose challenges. ${ }^{3,4,12-14}$ Of particular

60 concern is the fact that the HCl-butanol-acetone reagent often, but not always, gives higher

61 PA contents than thiolytic degradation; ${ }^{15,16}$ although opposite results have also been found

62 with galloylated PAs (unpublished results). Questions remain, therefore, about the true PA

63 contents in plants and foods. Currently, little is known about the quantities and composition

64 of unextractable PAs and alternative methods deserve evaluation. ${ }^{10,17}$

65 In contrast to the above degradation methods, nuclear magnetic resonance (NMR) has

66 the potential to provide direct evidence and accurate results for total, i.e. extractable plus

67 unextractable, PAs. Solution-state ${ }^{13} \mathrm{C}$ NMR spectroscopy has been used to determine the

68 relative purities, ${ }^{18,19} \mathrm{PC} / \mathrm{PD}^{18-21}$ and cis/trans flavan-3-ol ratios ${ }^{18,20,21}$ and $\mathrm{mDP}$ values of

69 extracted PAs. ${ }^{20,21}$ Whilst two dimensional gel-state NMR proved useful for assessing the

70 presence and composition of PAs in Lotus tissues, ${ }^{22}$ our proof-of-concept study showed that 
71 gel NMR spectra of sainfoin (Onobrychis viciifolia) tissues had signal resolution and matrix 72 interference problems.

73 Solid-state NMR experiments have been used for the direct analysis of plant materials 74 and require neither extraction nor derivatization of PAs. ${ }^{23-25}$ Cross-polarization magic-angle spinning (CPMAS) NMR techniques have previously been used to evaluate the efficiency of PA extraction in pine barks, ${ }^{23}$ softwood and barks from quebracho ${ }^{25}$ and humus ${ }^{26}$ as well as to characterize PAs in dietary fiber samples. ${ }^{27}$ In addition, differences in fingerprint spectra were used to distinguish between PA transformations of leather tannings ${ }^{28}$ and during fungal degradation. ${ }^{29}$ However, significant problems with poor resolution and frequent overlaps of multiple signals prevented any in depth quantitative estimates of the PA content and PC/PD ratios.

Sainfoin is a PA-containing forage legume, which is of interest for its nutraceutical and environmental properties. It engenders high voluntary intakes, ${ }^{30,31}$ has excellent nutritive value, ${ }^{30,31}$ lowers in vitro greenhouse gas emissions, ${ }^{32}$ prevents bloat in ruminants, ${ }^{33}$ lowers gastrointestinal nematodes, ${ }^{34}$ and can enhance the unsaturated fatty acid composition of meat 86 and milk products. ${ }^{35,36}$ The work presented here used six sainfoin accessions as a case study

87 for complex PA mixtures. ${ }^{37,38}$ Such complexity may have been the main reason for the observed discrepancies between the thiolysis and HCl-butanol-acetone assay results and still requires detailed experimental confirmation. ${ }^{39}$ Therefore, the aim of this study was to develop a procedure based on a ${ }^{13} \mathrm{C}$ CPMAS NMR technique for estimating PA content and composition directly, without chemical modification in different sainfoin accessions and to compare the results to thiolysis and HCl-butanol-acetone data. 
95 Plant Samples. Blackcurrant (Ribes nigrum) leaves were collected from Hildred PYO farm 96 (Goring-on-Thames, UK). Tilia (Tilia spp.) flowers were purchased from Flos (Mokrsko, 97 Poland) as described by Ropiak et al. ${ }^{8}$ Sainfoin (Onobrychis viciifolia) leaves and stems, 98 from six accessions, were provided by the National Institute of Agricultural Botany 99 (Cambridge, UK). Blackcurrant leaves and sainfoin plants were lyophilized or air-dried and 100 subsequently ground to pass a $1 \mathrm{~mm}$ sieve and ball-milled. Fine powders of ball-milled 101 blackcurrant leaves and Tilia flowers were also mixed on a weight basis (100/0, 70/30, 50/50, $10230 / 70$ and 0/100) for NMR analysis and the development of the procedure to elucidate PC/PD 103 ratios.

Chemicals and Reagents. Hydrochloric acid (36\%), formic acid, acetic acid, butan-1-ol, HPLC-grade acetone, HPLC-grade methanol, HPLC-grade dichloromethane, HPLC-grade hexane, HPLC-grade acetonitrile and ammonium chloride were purchased from Fisher Scientific Ltd (Loughborough, UK). ( \pm ) - Dihydroquercetin (98\%) was from Apin Chemicals (Abingdon, UK). Benzyl mercaptan and acetone- $d_{6}(99.9 \%)$ were supplied by Sigma-Aldrich (Poole, UK). Deuterium oxide $\left(\mathrm{D}_{2} \mathrm{O}\right)$ was from CK Isotopes (Ibstock, UK). Sephadex LH-20 was purchased from GE Healthcare (Little Chalfont, UK). Deionized water was purified in a Milli-Q system (Millipore, Watford, UK).

Proanthocyanidin Extraction and Purification. Finely ground plant tissue (50 g) was weighed into a conical flask. Acetone/water $(500 \mathrm{~mL}, 7: 3, \mathrm{v} / \mathrm{v})$ was added and the mixture was vigorously stirred for $1 \mathrm{~h}$. The mixture was filtered under vacuum. The filtrate was further extracted with dichloromethane $(250 \mathrm{~mL})$ to remove lipids and chlorophyll. to yield the "crude extract". 
This crude extract was diluted with deionized water (2 L) and filtered under vacuum.

121 The filtrate was loaded on a $400 \times 65 \mathrm{~mm}$ i.d., glass column which had been packed with $70 \mathrm{x}$

$12265 \mathrm{~mm}$ i.d., Sephadex LH-20 resin and was equipped with a sintered-glass frit. ${ }^{40}$ The column was then washed with deionized water $(2 \mathrm{~L})$ to elute sugars and low molecular mass phenolics. ${ }^{40}$ Gravity elution with acetone/water $(3: 7,1: 1$ and $8: 2, \mathrm{v} / \mathrm{v} ; 1 \mathrm{~L}$ each) yielded three PA fractions from each plant source; the first $200 \mathrm{~mL}$ of each eluate was discarded and PA fractions 1, 2 and 3 were collected in the next 500, 300, and $300 \mathrm{~mL}$, respectively. The organic solvent was removed on a rotary evaporator below $37.5^{\circ} \mathrm{C}$ and the PA fractions were frozen, freeze-dried and stored at $-20^{\circ} \mathrm{C}$. Fractions 2 that eluted with 1:1 acetone/water were designated as "purified PA fractions". Various aliquots from the purified blackcurrant and Tilia PA fractions (152:0, 36:83, 45:38, 63:25, 0:157 mg) were also mixed, in order to provide a range of nominal PC/PD values of $0 / 100,30 / 70,50 / 50,70 / 30$ and 100/0, for NMR analysis. The calculated PC and PD contents within purified PA fraction (in g PCs or PDs/100 g purified PA fraction) were based on the PC and PD contents from thiolysis (Tilia: 97.4 g PCs/100 g of purified PA fraction and blackcurrant: $94.9 \mathrm{~g}$ PDs/100 g of purified PA fraction).

Thiolysis of Purified Proanthocyanidins. Thiolysis reactions on purified PA fractions that eluted with acetone/water $(1: 1 \mathrm{v} / \mathrm{v})$ were performed according to Novobilský et al. ${ }^{41}$ Purified PA fractions (4 mg) were weighed into a $10 \mathrm{~mL}$ screw-capped vial, dissolved in methanol $140(1.5 \mathrm{~mL})$ and acidified with $\mathrm{HCl}(0.5 \mathrm{~mL}, 3.3 \%$ in methanol, $\mathrm{v} / \mathrm{v})$. This was followed by addition of benzyl mercaptan $(50 \mu \mathrm{L})$ and the reaction mixture was stirred in a water-bath for

$1421 \mathrm{~h}$ at $40{ }^{\circ} \mathrm{C}$. The reaction was quenched by adding ultrapure water $(2.5 \mathrm{~mL})$ to the mixture at 143 room temperature. The analysis and quantification of thiolysis reaction products were 
144 performed with reverse-phase HPLC according to Gea et al. ${ }^{5}$ The operating conditions and 145 parameters of HPLC analysis were described by Williams et al. ${ }^{42}$

147 In planta Thiolysis of Sainfoin Proanthocyanidins. Milled freeze-dried sainfoin plant

148 material (200 mg) was weighed into a $10 \mathrm{~mL}$ screw-capped vial, dissolved in methanol (2

$149 \mathrm{~mL})$ and acidified with $\mathrm{HCl}(1 \mathrm{~mL}, 3.3 \%$ in methanol, $\mathrm{v} / \mathrm{v})$. This was followed by addition of 150 benzyl mercaptan $(100 \mu \mathrm{L})$ and the mixture was stirred in a water-bath for $1 \mathrm{~h}$ at $40^{\circ} \mathrm{C}$. The

151 reaction was stopped by transferring the vials into an ice-bath and $1 \%$ formic acid in ultrapure water $(9 \mathrm{~mL})$ was added at room temperature. The samples were centrifuged $(3000$ rpm, $5 \mathrm{~min}$ ) and $1 \mathrm{~mL}$ of the mixtures added to HPLC vials for LC-MS analysis. (Hichrom, Theale, UK) fitted to a 150 x $3 \mathrm{~mm}$ i.d., $5 \mu \mathrm{m}$, ACE EXCEL Ultra-Inert UHPLC compatible guard cartridge (Hichrom, Theale, UK). The column temperature was set at 60 ${ }^{\circ} \mathrm{C}$. The HPLC system consisted of a G1379A degasser, a G1312A binary pump, a G1313A ALS autoinjector, a G1314A VWD UV detector and a G1316A column oven and an 1100 series MSD API-ES mass spectrometer (Agilent Technologies, Waldbronn, Germany). Data were acquired and processed with ChemStation software (version A 10.01 Rev. B.01.03). reaction products eluted with the following gradient: $0-7 \mathrm{~min}, 2.5 \% \mathrm{~B}$; $7-15 \mathrm{~min}, 2.5-5 \% \mathrm{~B}$; 15-22 $\min , 5-10 \% \mathrm{~B} ; 22-40 \min , 10-40 \% \mathrm{~B} ; 40-45 \min , 40-100 \%$ B; 45-49, 100-2.5\% B; 491000. The mass spectrometer operating conditions were as follows: $3000 \mathrm{~V}$ for capillary voltage, nebulizer gas pressure at $35 \mathrm{psi}$, drying gas at $12 \mathrm{~mL} / \mathrm{min}$ and dry heater temperature 
at $350{ }^{\circ} \mathrm{C}$. Flavan-3-ols and their benzyl mercaptan adducts were identified by their retention times, ultraviolet-visible (UV) spectra recorded at $280 \mathrm{~nm}$ and molecular masses and they were quantitated using published response factors against dihydroquercetin. ., $^{8}$

\section{In planta Sainfoin Proanthocyanidin Analysis with the HCl-Butanol-Acetone Assay. The} HCl-butanol-acetone assay followed the procedure of Grabber et al. ${ }^{22}$ with minor modifications. Briefly, lyophilized sainfoin plant tissue was weighed $(10 \mathrm{mg})$ into a $10 \mathrm{~mL}$ screw-capped vial. The reagent mixture was prepared by mixing ammonium ferric sulfate $(150 \mathrm{mg})$ in ultrapure water $(3.3 \mathrm{~mL})$, hydrochloric acid $(12 \mathrm{M}, 5 \mathrm{~mL})$, butan-1-ol $(42 \mathrm{~mL})$ and acetone $(50 \mathrm{~mL})$. An aliquot of the reagent $(10 \mathrm{~mL})$ was added to the sainfoin sample. The sample was left at room temperature $(1 \mathrm{~h})$ to check for the presence of flavan-4-ols or flavan-3,4-diols as these generate false positives. ${ }^{43}$ Tubes were then stirred and heated at 70 ${ }^{\circ} \mathrm{C}$ for $2.5 \mathrm{~h}$ in the dark. Samples were left to cool to room temperature and centrifuged (3000 rpm, $1 \mathrm{~min}$ ). Absorbance of the supernatant was recorded by scanning from $450-650 \mathrm{~nm}$ using a V530 spectrophotometer (Jasco, Great Dunmow, UK). The HCl-butanol-acetone reagent was used as a blank and all samples were run in duplicate. A sainfoin sample of known PA content and composition was used for quality control purposes.

\section{Analysis of Proanthocyanidins by ${ }^{13} \mathrm{C}$ Cross-Polarization Magic-Angle Spinning}

Nuclear Magnetic Resonance. The solid-state CPMAS NMR spectra were recorded on a Bruker Avance III $500 \mathrm{MHz}$ spectrometer (Bruker Biopsin, Rheinstetten, Germany) operating at carbon-13 Larmor frequency of $125.78 \mathrm{MHz}(11.75 \mathrm{~T})$. Crude extracts and purified PA fractions from Tilia and blackcurrant and ball-milled Tilia, blackcurrant and sainfoin plant tissue samples ( $\sim 80 \mathrm{mg}$ ) were compressed into standard $4 \mathrm{~mm}$ zirconia rotors prior to analysis. A standard bore Bruker MAS probe was used and rotors were spun at $10 \mathrm{kHz}$ rate. 
194 The proton $90^{\circ}$ pulse width was $3.7 \mu$ s at a power level of $32 \mathrm{~W}$. The variable amplitude CP 195 ramp (90-100) was used with a contact time of $1 \mathrm{~ms}$. In total, 4096 signal transients were 196 averaged into each spectrum with a 6 s relaxation delay at ambient temperature. All spectra 197 were referenced to an external adamantane signal (at $38.5 \mathrm{ppm}$ with respect to TMS) as a secondary reference. Dipolar dephasing experiments were run with identical parameters to ${ }^{13} \mathrm{C}$ CPMAS NMR experiments and dephasing filter time (tdd) of $45 \mu \mathrm{s}$ was optimized to attenuate the signals of all protonated carbons.

To accurately extract intensity of all signals, each experimental spectrum was fitted with a calculated spectrum that was constructed from the sum of signals with a Gaussian line shape. Numbers and positions of signals in the calculated spectrum corresponded directly to the number and positions of signals in the experimental spectrum. The width, amplitude and position of each signal in the calculated spectrum was optimized by minimizing the discrepancy between the experimental and calculated spectra using an "in house" written Matlab routine based on the least square method. A number of initial parameters were tested and the sets with the smallest discrepancy led to final results with a narrow range of the fitting error. Once the width and the amplitude of the fitted signal at $155 \mathrm{ppm}$ were known, the intensity was calculated.

The PA content of sainfoin plant tissue samples was estimated by comparing the signal intensity of the reference signal $I_{R}$ at $155 \mathrm{ppm}$ (from Tilia with $95 \mathrm{~g}$ PAs/100 g of purified PA fraction, determined by thiolysis) with the intensity $\mathrm{I}_{\mathrm{S}}$ of the $155 \mathrm{ppm}$ signal in the investigated sample.

The calculation of experimental error involved three factors: (i) the non-strictly quantitative character of the solid-state NMR experiments because of the cross-polarization signal enhancement (and possibly the miscalibration of the relaxation parameters); (ii) the 
small variation in setting hardware parameters, such as tuning and matching of the probe; and (iii) the numerical fitting of the spectra.

The recording of 2-3 spectra of the same sample with slightly different settings regarding the first two factors (including contact time and relaxation delay) resulted in an error of ca $2 \%$. The discrepancies of the spectra acquired with different parameters introduced an additional error of ca $2 \%$ after the fitting process. This accounted for a total error of ca $4 \%$ for the intensity measurements. The PA content was calculated by comparing the reference signal intensity to the intensity of the sample of interest. Therefore, the total experimental error (ca $8 \%$ or $8 \mathrm{~g}$ PAs/100 g of plant tissue) derived from the sum of the intensity errors between reference and sample intensity.

The influence of the spinning sidebands on the signal intensity was assessed by comparing the $155 \mathrm{ppm}$ signal intensity recorded at 10, 12 and $15 \mathrm{kHz}$ spinning rates for both crude extract and sainfoin plant tissue samples. Only small differences of less than $1 \%$, well within the experimental error were observed. At $10 \mathrm{kHz}$ spinning rate, the spinning sidebands of the signal at $155 \mathrm{ppm}$ were not fully removed and decreased the intensity by ca $12 \%$. However, the identical anisotropy of the chemical shift of $\mathrm{C} 5, \mathrm{C} 7$ and $\mathrm{C} 8 \mathrm{a}$ carbons in purified PA fraction and plant tissue PAs is expected (due to the same molecular structure) and by normalizing the intensity of the $155 \mathrm{ppm}$ signal from the sample of interest to the high purity reference with $95 \mathrm{~g}$ PAs/100 g of purified PA fraction from Tilia, the contribution of these factors to the intensity error could be neglected.

However, it should be noted that ${ }^{13} \mathrm{C}$ CPMAS NMR is not strictly quantitative and, therefore, it is unlikely but not impossible that the discrepancies could have exceeded to a small extent the range of the estimated experimental error.

\section{RESULTS AND DISCUSSION}


243 Assignment of Signals in the Solid-State NMR Spectrum. The ${ }^{13}$ C CPMAS NMR spectra

244 of the purified PA fractions from Tilia and blackcurrant consisted of approximately ten

245 resolved resonances each centered between 170 and $0 \mathrm{ppm}$ and showed several PA

246 fingerprint signals (Figure 2B). Characteristic resonances at 155, 144 and 132 ppm were

247 clearly observed in the spectra of all three sample types, i.e. purified PA fractions, crude

248 extracts and plant tissues (Figure 3). The signal at $155 \mathrm{ppm}$ originated from the non-

249 protonated carbons C5, C7, C8a of the flavan-3-ol structure (Figure 2A). ${ }^{25,27,44}$ The signal at

$250144 \mathrm{ppm}$ was from the resonance of the non-protonated carbons $\mathrm{C}^{\prime}$, $\mathrm{C}^{\prime}$ of blackcurrant PAs

251 and the non-protonated carbons $\mathrm{C}^{\prime}{ }^{\prime}, \mathrm{C}^{\prime}$ of Tilia PAs. ${ }^{24,25,44}$ The most distinctive signal at

252132 ppm originated from the non-protonated carbons $\mathrm{C}^{\prime}, \mathrm{C}^{\prime}$ in blackcurrant PAs but only

253 from the non-protonated carbon $\mathrm{C1}^{\prime}$ in Tilia $\mathrm{PAs}^{24,25,44}$

experiments were performed. The experimental parameters were optimized to detect only signals from non-protonated carbons (Figure 2B). The resulting data confirmed our initial identification and were in good agreement with spectra in reports on pecan nutshell PDs ${ }^{45}$ and Photinia leaf PCs. ${ }^{44}$ Weak signals of not completely removed spinning sidebands were detected in the 80-40 ppm region. Some very weak contributions from the protonated carbons were also visible in the 40-20 ppm region and could have been caused by a small miscalibration of parameters for the dephasing filter.

The resonances from protonated carbons were spread across the $120-0 \mathrm{ppm}$ region and showed line broadening and overlap, especially for the crude extracts and milled plant tissues (Figures 2B and 3). This was likely due to interferences from other plant components such as lignin, pectin, cutin, cellulose and hemicellulose as previously reported in crude extracts and milled plant samples. ${ }^{25,28,44}$ However, our signal assignments of the purified PA 
267 fractions from Tilia and blackcurrant were consistent with the much better resolved ${ }^{1} \mathrm{H}-{ }^{13} \mathrm{C}$

268 HSQC solution NMR spectra of the same samples.

269

270 Estimation of Proanthocyanidin Content in the Presence of Lignin. Accurate

271 quantification of PAs in plant matrices is of great interest and several techniques have been

272 used including solid-state NMR. The region between 160-120 ppm is understood to be the

273 most suitable despite some possible lignin or lignin-PA complex contributions especially in

274 milled plant samples. ${ }^{25,44}$ In particular, Wawer et al. ${ }^{27}$ postulated that resonances at 155 and

275144 ppm in solid-state NMR dipolar dephased spectra from Aronia and blackcurrant fiber

276 powders could include responses from C3, 5-OMe and C4-OH carbons of lignin. However,

277 this interference was on a smaller scale (i.e. there were no significant changes to the signal

278 pattern) compared to resonances below $120 \mathrm{ppm}$ (Figure 3) where the appearance changed

279 completely between purified PA fractions and milled plant tissues.

280 The characteristic signals at 155,144 and $132 \mathrm{ppm}$ in the spectra of the purified PA

281 fractions could only have derived from PAs as large polymeric lignin molecules were not

282 expected to be soluble in acetone/water. ${ }^{27,46}$ Our strict, two step purification process also

283 assured that the low molecular weight phenolics or lignin fragments which may have been

284 present in small quantities in crude extracts were predominantly removed in the purified PA

285 fractions. The intensities of the $132 \mathrm{ppm}$ signal spinning side bands at $211 \mathrm{ppm}$ (left spinning

286 side band) and $53 \mathrm{ppm}$ (right spinning side band) were exactly the same ( $0.02 \%$ difference $)$

287 which proves that there is no, or only negligible, lignin contribution to the NMR spectra of

288 the purified PA fractions. Figure 3 shows the comparison of the normalized amplitude of

289 these characteristic signals between purified PA fractions, crude extracts and milled plant

290 tissues. However, it was not possible to estimate the contribution of impurities or plant matrix

291 components to the intensity because currently there is no technique that can provide 
completely accurate data on PA concentrations in the plant tissues. However, a contribution of lignin in this region of the spectrum was expected between 155 and $144 \mathrm{ppm}$ as postulated, ${ }^{27}$ and it should affect the width of the resonances due to overlap. Therefore, measuring the change of the signal width in purified PA fractions, crude extracts and milled plant tissues could provide an estimate of lignin interference. In our case, the estimated increase in the width of the 155 and 144 ppm signals was $<15 \%$ for crude extracts and $<25 \%$ for plant tissues, and corresponded well to the increased intensity of the lignin signal at 53 ppm, which was especially evident for the Tilia plant tissues (Figure 3B).

This simple estimate showed that the lignin interference had to be taken into account as a correction to the PA content in plant samples. To test the accuracy of this assumption, the content of extractable PAs in the crude extract from blackcurrant was estimated with ${ }^{13} \mathrm{C}$ CPMAS NMR and compared to the thiolysis result. The PA content determined by NMR without correction was $39.7 \mathrm{~g}$ PAs/100 g crude extract and with the $15 \%$ reduction was 33.7 $\mathrm{g}$ PAs $/ 100 \mathrm{~g}$ crude extract (with an error of $\pm 8 \mathrm{~g}$ PAs/100 g). The latter value was in excellent agreement with the thiolysis result of $29.2 \mathrm{~g} \mathrm{PAs} / 100 \mathrm{~g}$ crude extract. This demonstrates that both techniques can be used for the analysis of extractable PAs.

Although this simple calculation may take into account a lignin contribution, other factors could also influence the width of the resonance line, e.g. relaxation and mobility issues can arise from large polymeric molecules ${ }^{25}$ and small variation in the shimming quality. ${ }^{47}$ Further, one needs to be aware that the thiolysis and $\mathrm{HCl}$-butanol-acetone assays have their own limitations, especially when applied directly to plant tissues.

Despite problems arising from possible plant matrix interferences in the milled plant tissues, it may be concluded that the $155 \mathrm{ppm}$ signal of the purified PA fractions was a suitable marker to estimate PA contents in unknown milled plant tissues. Therefore, the PA content of sainfoin plant tissue samples was estimated by comparing the intensity of a 
317 reference signal, $\mathrm{I}_{\mathrm{R}}$, of the purified PA fraction ( $95 \mathrm{~g}$ PAs/100 $\mathrm{g}$ as determined by thiolysis)

318 from Tilia and the intensity of the $\mathrm{I}_{\mathrm{S}}$ signal of the investigated sample. ${ }^{23}$ The content error 319 was estimated to be ca $8 \mathrm{~g}$ PAs/100 g plant tissue.

320 The PA content of selected sainfoin plant tissues determined by ${ }^{13} \mathrm{C}$ CPMAS NMR

321 (without and with a 25\% reduction for the lignin correction) was then compared to results

322 from the thiolysis and the HCl-butanol-acetone assays (Table 1). Selected spectra are shown

323 in Figure 4. Clearly, solid-state NMR consistently gave the largest PA content in all sainfoin

324 plant tissue samples and thiolysis gave the smallest. Most HCl-butanol-acetone values were

325 higher than the thiolysis data ${ }^{16}$ and accounted for ca $50 \%$ of the NMR data after lignin

326 correction. The results varied greatly between the sainfoin accessions for all methods, but it is

327 worth pointing out that the three Zeus samples (S1, S2 and S6) gave consistent results with

328 the NMR and HCl-butanol-acetone but not the thiolysis technique.

329 The above results illustrate the complexity of determining PA content directly in

330 plants. Our NMR results can be regarded as an upper limit of PA content compared to the

331 other techniques (Table 1) and is more likely to measure previously undetected unextractable

332 PAs because NMR does not require any chemical modification of the sample. Solid-state

333 NMR has already proved useful for estimating differences in PA contents within species, i.e.

334 for samples with similar PA compositions. ${ }^{25,28}$ Our approach to account for a lignin

335 contribution could improve the way NMR could be used for PA measurements more

336 generally, including for the first time full quantitative elucidation. The validity of our

337 approach is illustrated by the analysis of the amplitude of the lignin signal at $53 \mathrm{ppm}$ for

338 samples S1, S3 and S4 (Figure 4). The strongest lignin signal was detected in the S1 sample

339 and the weakest and approximately equal signals in the S3 and S4 samples. Had lignin

340 interference been the predominant factor in the measurement of PA content then S1 should

341 have had more PAs than the S3 and S4 samples. As evident from the 155 and $145 \mathrm{ppm}$ 
342 signals this was not the case as the S3 sample with the smallest lignin contribution had the 343 largest PA content.

344 There are several possible reasons for the differences between the NMR and the 345 thiolysis or HCl-butanol-acetone data. Whilst our results account for a lignin contribution at $346155 \mathrm{ppm}$ on the basis of the reference Tilia and blackcurrant samples, they do not rule out 347 contributions from other matrix components in the investigated sainfoin plant tissues. ${ }^{24,27}$ 348 Secondly, solid-state NMR experiments are not strictly quantitative because the efficiency of 349 the cross-polarization depends on proton abundance in the neighboring environment, the 350 molecular dynamics and the relaxation behavior for improving the ${ }^{13} \mathrm{C}$ signal. ${ }^{25,28}$ These 351 factors are difficult to fully control in NMR experiments and are unlikely to be the same for 352 all carbons, and will also vary between different plant matrices. Therefore, it is possible that 353 the proton environment of the more complex and possibly larger sainfoin PAs (mDP of 12 to 354 27) could have resulted in a larger signal enhancement (and consequently PA content) 355 compared to the purified Tilia PAs (mDP of 8), but it is unlikely that this factor alone increased the NMR signal by $100 \%$ (Table 1$)$.

Another explanation could arise from the limitations of the thiolysis and HCl-butanolacetone assays in quantitating PAs directly in plant tissues. ${ }^{3,4}$ It has been shown that longer reaction times during thiolysis with benzyl mercaptan resulted in considerably higher concentrations. ${ }^{5}$ In addition, the existence of thiolysis-resistant PAs has also been reported. ${ }^{9}$ The previous versions of the HCl-butanol assay often underestimated total PA content when applied directly to plant or extracted residue samples, possibly because of incomplete interaction with bound PAs. ${ }^{12}$ However, the present HCl-butanol-acetone assay used a recent

364 modification by Grabber et al., ${ }^{22}$ who demonstrated that inclusion of acetone achieved complete degradation of unextractable PAs from two Lotus species. Nevertheless, it is possible that sainfoin may have more diverse PA mixtures than Lotus, ${ }^{48}$ which could explain 
367 the observed differences between the NMR, thiolysis and HCl-butanol-acetone results.

368 Overall, the important point here is that the NMR results suggested that NMR allows

369 accounting for all extractable and unextractable PAs, whereas the thiolysis and HCl-butanol-

370 acetone assays may be underestimating PA contents.

371

372 Estimation of Mean Degree of Polymerization. The mean degree of polymerization (mDP)

373 can be obtained by integrating the $\mathrm{C} 3$ signals from PA extension units at $73 \mathrm{ppm}$ and the

374 corresponding signals of PA terminal units at $67 \mathrm{ppm}$ in solution NMR. ${ }^{20,21,26}$ However,

375 significant signal overlap from various plant constituents in milled plant tissues ${ }^{26}$ and

376 consequently poor resolution of that region in the ${ }^{13} \mathrm{C}$ CPMAS NMR spectra (Figure 3 )

377 prevented estimation of mDP values.

Estimation of procyanidin/prodelphinidin ratios. The procedure to estimate $\mathrm{PC}$ to $\mathrm{PD}$ ratios within PAs was based on their different hydroxylation patterns, which were clearly distinguishable in the $140-100$ ppm region of the ${ }^{13} \mathrm{C}$ CPMAS NMR spectra (Figure 2B). The resonance at $132 \mathrm{ppm}$ was assigned to $\mathrm{C}^{\prime}{ }^{\prime}$ and $\mathrm{C}^{\prime}{ }^{\prime}$ carbons of PDs from blackcurrant, but in Tilia $\mathrm{PCs}$ this resonance was assigned only to $\mathrm{C1}^{\prime}$ carbon and had only half the intensity of

the PDs signal. ${ }^{44,45}$ This difference in the $132 \mathrm{ppm}$ signal intensity directly reflected the PD and PC composition because the PA contents were comparable (i.e. blackcurrant $87 \mathrm{~g}$ PAs/100 g of purified PA fraction; and Tilia $95 \mathrm{~g}$ PAs/100 $\mathrm{g}$ of purified PA fraction); the molar percentages obtained by thiolysis were 94.9\% PDs and 97.4\% PCs for the purified PA fractions, from blackcurrant and Tilia respectively.

This observation was validated by thiolysis and ${ }^{1} \mathrm{H}-{ }^{13} \mathrm{C}$ HSQC solution NMR 
$39150 / 50,30 / 70$ and 0/100, prepared by mixing purified PA fractions from Tilia and

392 blackcurrant.

393 However, the solution NMR methods, such as used by Czochanska et al. ${ }^{20}$ and Zeller

394 et al., ${ }^{23}$ to estimate $\mathrm{PC} / \mathrm{PD}$ ratios, which rely on the high resolution of the solution NMR

395 spectra could not be transferred directly to the solid-state NMR experiments. The

396 experimental resolution of the recorded solid-state NMR spectra was in the order of $12.5 \mathrm{~Hz}$

397 (or $0.1 \mathrm{ppm}$ ) but the typical linewidth was ca $550 \mathrm{~Hz}$ (or $4.5 \mathrm{ppm}$ ), as expected for large

398 polymeric molecules. In addition to that, the spectra of milled plant tissues show significant

399 overlap with other signals from the plant matrix below $110 \mathrm{ppm}$, which prevents any

400 meaningful PC/PD analysis (Figures 3 and 5A). Therefore, it was impossible to calculate

$401 \mathrm{PC} / \mathrm{PD}$ ratio on the basis of the $\mathrm{C}^{\prime}-\mathrm{C}^{\prime}$ carbons as used in solution NMR experiments.

402 The experiment on the artificial mixtures of purified PA fractions with nominal

$403 \mathrm{PC} / \mathrm{PD}$ values was repeated using the solid-state NMR technique. The intensity ratios

404 between signals at 132 and $155 \mathrm{ppm}$ were selected as a calibration standard (to minimize the

405 experimental errors) because they were expected to vary linearly between a value of $1 / 3$ or ca

4060.33 for pure PCs, and $2 / 3$ or ca 0.67 for pure PDs reflecting the number of carbons

407 contributing to each signal (Figures $2 \mathrm{~B}$ and $5 \mathrm{~A}$ ). The resulting $\mathrm{I}_{132} / \mathrm{I}_{155}$ experimental ratios

408 were within the theoretical limits (Figure 5B) and showed excellent linear dependence when

409 plotted as a function of the nominal PC/PD values.

410 However, to extend the procedure to estimate the unknown PC/PD ratios of milled

411 sainfoin tissues, it was necessary to repeat the experiment on the artificial mixtures but this

412 time these were prepared on a plant weight $(\mathrm{mg})$ basis using the milled Tilia and blackcurrant

413 tissues. This allowed us to assess and overcome several problems, such as imprecisions in the

414 nominal PC/PD values and plant matrix interference, which varied between different plants

415 and could obscure any direct calculation of the unknown PC/PD ratio using only milled Tilia 
416 or blackcurrant plant tissues. It was assumed that the nominal PC/PD values (again equal to $417100 / 0,70 / 30,50 / 50,30 / 70$ and $0 / 100)$ in these plant tissues would be the same as in the 418 purified PA fraction mixtures. A similar linear dependence of the $\mathrm{I}_{132} / \mathrm{I}_{155}$ on the nominal $419 \mathrm{PC} / \mathrm{PD}$ values was indeed observed for the milled plant tissues compared to the purified PA 420 fraction mixtures (Figure 5B). The large offset between both curves shows that there is a 421 possible interference of the plant matrix. However, both curves showed a similar slope, which 422 confirmed that extraction and purification had no effect on the PC/PD ratio in Tilia and 423 blackcurrant mixtures, and that the matrix effect on intensity was almost uniform across these 424 PC/PD ratios. Therefore, the gradient of the $\mathrm{I}_{132} / \mathrm{I}_{155}$ intensity ratio as a function of nominal $425 \mathrm{PC} / \mathrm{PD}$ values could be regarded as a universal tool for setting up a calibration curve to 426 estimate unknown PC/PD ratios in other plant samples such as sainfoin.

Table 1 shows a comparison between the PC content in sainfoin samples from the ${ }^{13} \mathrm{C}$ 428 CPMAS NMR spectra and the thiolysis data. It can be seen that NMR estimated much higher 429 PC contents in purified PA fractions than thiolysis in four of the eight samples, but had a rather low accuracy with an estimated experimental error of $\pm 16 \mathrm{mg}$ PCs/100 mg purified PA fraction. The biggest contributor to the estimated error was the uncertainty in the fitting of the 132 ppm signal, which overlapped with other signals from the plant matrices (Figures 4 and $6 A)$. This was not surprising given the large offset already observed for the $\mathrm{I}_{132} / \mathrm{I}_{155}$ intensity ratio dependence on nominal $\mathrm{PC} / \mathrm{PD}$ values between purified PA fractions and milled plant 435 tissues (Figure 5B). However, the degree and pattern of overlap was much larger and variable in the sainfoin compared to the reference Tilia and blackcurrant plant tissues (Figure 5A).

437 This problem was particularly evident when comparing the NMR spectra of the S3 and S1 438 tissues (Figure 4); and was also highlighted in Figure 6, which compared the NMR spectra of sainfoin leaves and stems. Obviously, it was only possible in the case of the fairly resolved 440 structure to extract the correct intensity of the signal at $132 \mathrm{ppm}$ from the spectrum. 
441 Therefore, a better resolution of the NMR spectra will be required to improve the accuracy of 442 the estimated PC molar percentage or PC/PD ratio beyond a qualitative assessment.

443 However, the comparison of sainfoin leaf and stem spectra also demonstrated the 444 potential of the ${ }^{13} \mathrm{C}$ CPMAS NMR approach to gain a rapid qualitative assessment (Figure 6).

445 The stem spectra showed a very different pattern of resonances in the region between 160 $446120 \mathrm{ppm}$. This was most likely due to poorer resolution of signals at 144 and $132 \mathrm{ppm}$ in 447 stems, which tend to have higher lignin content than leaves, and also corresponded to lower 448 PA content in stems than leaves ${ }^{37}$ and a greater contribution of plant matrix interferences. 449 This study reported a first attempt to develop a procedure based on ${ }^{13} \mathrm{C}$ CPMAS NMR 450 technique for the direct screening of PAs in sainfoin plant tissues. By using contrasting 451 signature PA spectra from blackcurrant and Tilia reference samples, a calibration for PAs was 452 developed based on signal intensities at 155 and $132 \mathrm{ppm}$. There were surprisingly large 453 differences between the PA content obtained by the thiolysis or HCl-butanol-acetone assays 454 and ${ }^{13} \mathrm{C}$ CPMAS NMR results. These differences could be due to interfering plant matrix 455 components, size and mobility differences in reference and sainfoin PAs, and/or presence of 456 unextractable PAs in sainfoin plant tissues. It is very unlikely that various sizes and mobility 457 differences would influence the cross-polarization enhancement to such an extent that it could 458 account for the observed PA content differences. A simple correction to account for the 459 matrix interference based on the linewidth difference between the purified PA fraction and 460 milled plant tissue has been used. However, even with the applied correction the differences 461 between the ${ }^{13} \mathrm{C}$ CPMAS NMR and thiolysis or HCl-butanol assays indicated that the two 462 degradation methods may not detect the entire PA present in some plants. Therefore, only ${ }^{13} \mathrm{C}$ 463 CPMAS NMR provided full information on both extractable and unextractable PAs in 464 sainfoin plant tissues. 
In conclusion, this newly developed procedure based on ${ }^{13} \mathrm{C}$ CPMAS NMR technique

466

467

468

469

470

471

472

473

474

475

476

477

478

479

480

481

482

483

484

485

486

487

488

489 has proved to be a useful tool for estimating the upper limit of PA content directly in whole

plants and could be of interest for probing the bioactivities of unextractable PAs.

ACKNOWLEDGMENTS: We thank Hildred PYO farm for permission to collect the blackcurrant leaf samples. Use of the NMR spectrometer at the Chemical Analysis Facility (CAF), University of Reading is gratefully acknowledged.

AUTHOR INFORMATION: *Alternate Corresponding author (Tel.: +31 (0)317486721;

Email: christos.fryganas@,wur.nl).

FINANCIAL SUPPORT: This work was supported by a European Union Marie Curie training network (PITN-GA-2011-289377, “LegumePlus”).

CONFLICTS OF INTEREST: The authors declare no conflict of interest.

SUPPORTING INFORMATION DESCRIPTION: ${ }^{1} \mathrm{H}-{ }^{13} \mathrm{C}$ Heteronuclear Single Quantum Coherence (HSQC) Nuclear Magnetic Resonance Analysis of the Purified PA Fraction Mixtures; Chromatogram of the Thiolysis Reaction Products from the Blackcurrant Purified PA Fraction; Chromatogram of the Thiolysis Reaction Products from the Tilia Purified PA Fraction. 


\section{References}

491 (1) Cheynier, V.; Tomas-Barberan, F. A.; Yoshida, K. Polyphenols: From plants to a variety 492 of food and nonfood uses. J. Agric. Food Chem. 2015, 63, 7589-7594.

493 (2) Mueller-Harvey, I. Unravelling the conundrum of tannins in animal nutrition and health. 494 J. Sci. Food Agric. 2006, 86, 2010-2037.

495 (3) Hummer, W.; Schreier, P. Analysis of proanthocyanidins. Mol. Nutr. Food Res. 2008, 52, $496 \quad 1381-1398$.

497 (4) Schofield, P.; Mbugua, D. M.; Pell, A. N. Analysis of condensed tannins: A review. Anim. $498 \quad$ Feed Sci. Technol. 2001, 91, 21-40.

499 (5) Gea, A.; Stringano, E.; Brown, R. H.; Mueller-Harvey, I. In situ analysis and structural 500 elucidation of sainfoin (Onobrychis viciifolia) tannins for high-throughput germplasm 501 screening. J. Agric. Food Chem. 2011, 59, 495-503.

502 (6) Karonen, M.; Leikas, A.; Loponen, J.; Sinkkonen, J.; Ossipov, V.; Pihlaja, K. Reversed503 phase HPLC-ESI/MS analysis of birch leaf proanthocyanidins after their acidic degradation 504 in the presence of nucleophiles. Phytochem. Anal. 2007, 18, 378-386.

505 (7) Meagher, L. P.; Lane, G.; Sivakumaran, S.; Tavendale, M. H.; Fraser, K. Characterization 506 of condensed tannins from Lotus species by thiolytic degradation and electrospray mass 507 spectrometry. Anim. Feed Sci. Technol. 2004, 117, 151-163.

508 (8) Ropiak, H. M.; Ramsay, A.; Mueller-Harvey, I. Condensed tannins in extracts from 509 European medicinal plants and herbal products. J. Pharm. Biomed. Anal. 2016, 121, 225510331.

511 (9) Matthews, S.; Mila, I.; Scalbert, A.; Donnelly, D. M. X. Extractable and non-extractable 512 proanthocyanidins in barks. Phytochemistry 1997, 45, 405-410. 
513 (10) Perez-Jimenez, J.; Arranz, S.; Saura-Calixto, F. Proanthocyanidin content in foods is 514 largely underestimated in the literature data: An approach to quantification of the missing 515 proanthocyanidins. Food Res. Int. 2009, 42, 1381-1388.

516 (11) Ramsay, A.; Drake, C.; Grosse Brinkhaus, A.; Girard, M.; Copani, G.; Dohme-Meier, F.;

517 Bee, G.; Niderkorn, V.; Mueller-Harvey, I. Sodium hydroxide enhances extractability and 518 analysis of proanthocyanidins in ensiled sainfoin (Onobrychis viciifolia). J. Agric. Food 519 Chem. 2015, 63, 9471-9479.

520 (12) Makkar, H. P. S.; Gamble, G.; Becker, K. Limitation of the butanol-hydrochloric acid521 iron assay for bound condensed tannins. Food Chem. 1999, 66, 129-133.

522 (13) Callemien, D.; Guyot, S.; Collin, S. Use of thiolysis hyphenated to RP-HPLC-ESI523 MS/MS for the analysis of flavanoids in fresh lager beers. Food Chem. 2008, 110, 10125241018.

525 (14) Wayne McGraw, G.; Steynberg, J. P.; Hemingway, R. W. Condensed tannins: A novel 526 rearrangement of procyanidins and prodelphinidins in thiolytic cleavage. Tetrahedron Lett. 527 1993, 34, 987-990.

528 (15) Klongsiriwet, C. Phytochemical analysis of a willow germplasm collection and its 529 pharmacological activities. Ph.D. Thesis, The University of Reading, UK, June 2016. 530 (16) Azuhnwi, B. N.; Boller, B.; Dohme-Meier, F.; Hess, H. D.; Kreuzer, M.; Stringano, E.; 531 Mueller-Harvey, I. Exploring variation in proanthocyanidin composition and content of 532 sainfoin (Onobrychis viciifolia). J. Sci. Food Agric. 2013, 93, 2102-2109.

533 (17) Hellstrom, J. K.; Mattila, P. H. HPLC determination of extractable and unextractable 534 proanthocyanidins in plant materials. J. Agric. Food Chem. 2008, 56, 7617-7624.

535 (18) Zeller, W. E.; Ramsay, A.; Ropiak, H. M.; Fryganas, C.; Mueller-Harvey, I.; Brown, R. 536 H.; Drake, C.; Grabber, J. H. ${ }^{1} \mathrm{H}^{13} \mathrm{C}$ HSQC NMR spectroscopy for estimating 
537 procyanidin/prodelphinidin and cis/trans-flavan-3-ol ratios of condensed tannin samples:

538 Correlation with thiolysis. J. Agric. Food Chem. 2015, 63, 1967-1973.

539 (19) Hellstrom, J.; Sinkkonen, J.; Karonen, M.; Mattila, P. Isolation and structure elucidation

540 of procyanidin oligomers from Saskatoon berries (Amelanchier alnifolia). J. Agric. Food

541 Chem. 2007, 55, 157-164.

542 (20) Czochanska, Z.; Foo, L. Y.; Newman, R. H.; Porter, L. J. Polymeric proanthocyanidins 543 stereochemistry, structural units, and molecular-weight. J. Chem. Soc., Perkin Trans. 1 1980, $544 \quad 2278-2286$.

545 (21) Qaadan, F.; Nahrstedt, A.; Schmidt, M.; Mansoor, K. Polyphenols from Ginkgo biloba. 546 Sci. Pharm. 2010, 78, 897-907.

547 (22) Grabber, J. H.; Zeller, W. E.; Mueller-Harvey, I. Acetone enhances the direct analysis of 548 procyanidin- and prodelphinidin-based condensed tannins in Lotus species by the butanol549 HCl-iron assay. J. Agric. Food Chem. 2013, 61, 2669-2678.

550 (23) Grigsby, W. J.; Hill, S. J.; McIntosh, C. D. NMR estimation of extractables from bark: 551 Analysis method for quantifying tannin extraction from bark. J. Wood Chem. Technol. 2003, $552 \quad 23,179-195$.

553 (24) Parfitt, R. L.; Newman, R. H. ${ }^{13}$ C NMR study of pine needle decomposition. Plant Soil $554 \mathbf{2 0 0 0}, 219,273-278$.

555 (25) Reid, D. G.; Bonnet, S. L.; Kemp, G.; van der Westhuizen, J. H. Analysis of commercial 556 proanthocyanidins. Part 4: Solid state ${ }^{13} \mathrm{C}$ NMR as a tool for in situ analysis of 557 proanthocyanidin tannins, in heartwood and bark of quebracho and acacia, and related 558 species. Phytochemistry 2013, 94, 243-248.

559 (26) Lorenz, K.; Preston, C. M. Characterization of high-tannin fractions from humus by 560 carbon-13 cross-polarization and magic-angle spinning nuclear magnetic resonance. $J$. 561 Environ. Qual. 2002, 31, 431-436. 
562 (27) Wawer, I.; Wolniak, M.; Paradowska, K. Solid state NMR study of dietary fiber powders 563 from aronia, bilberry, black currant and apple. Solid State Nucl. Magn. Reson. 2006, 30, 106564113.

565 (28) Romer, F. H.; Underwood, A. P.; Senekal, N. D.; Bonnet, S. L.; Duer, M. J.; Reid, D. 566 G.; van der Westhuizen, J. H. Tannin fingerprinting in vegetable tanned leather by solid state 567 NMR spectroscopy and comparison with leathers tanned by other processes. Molecules 2011, $568 \quad 16,1240-1252$.

569 (29) Gamble, G. R.; Akin, D. E.; Makkar, H. P.; Becker, K. Biological degradation of tannins 570 in sericea lespedeza (Lespedeza cuneata) by the white rot fungi Ceriporiopsis subvermispora 571 and Cyathus stercoreus analyzed by solid-state ${ }^{13} \mathrm{C}$ nuclear magnetic resonance spectroscopy. 572 Appl. Environ. Microbiol. 1996, 62, 3600-3604.

573 (30) Hayot Carbonero, C.; Mueller-Harvey, I.; Brown, T. A.; Smith, L. Sainfoin (Onobrychis 574 viciifolia): A beneficial forage legume. Plant Genet. Resour. 2011, 9, 70-85.

575 (31) Wang, Y. X.; McAllister, T. A.; Acharya, S. Condensed tannins in sainfoin:

576 Composition, concentration, and effects on nutritive and feeding value of sainfoin forage. 577 Crop Sci. 2015, 55, 13-22.

578 (32) Chung, Y. H.; Mc Geough, E. J.; Acharya, S.; McAllister, T. A.; McGinn, S. M.;

579 Harstad, O. M.; Beauchemin, K. A. Enteric methane emission, diet digestibility, and nitrogen 580 excretion from beef heifers fed sainfoin or alfalfa. J. Anim. Sci. 2013, 91, 4861-4874.

581 (33) McMahon, L. R.; McAllister, T. A.; Berg, B. P.; Majak, W.; Acharya, S. N.; Popp, J. D.; 582 Coulman, B. E.; Wang, Y.; Cheng, K. J. A review of the effects of forage condensed tannins 583 on ruminal fermentation and bloat in grazing cattle. Can. J. Plant Sci. 2000, 80, 469-485.

584 (34) Manolaraki, F.; Sotiraki, S.; Stefanakis, A.; Skampardonis, V.; Volanis, M.; Hoste, H.

585 Anthelmintic activity of some Mediterranean browse plants against parasitic nematodes.

586 Parasitology 2010, 137, 685-696. 
587 (35) Girard, M.; Dohme-Meier, F.; Silacci, P.; Ampuero Kragten, S.; Kreuzer, M.; Bee, G. 588 Forage legumes rich in condensed tannins may increase n-3 fatty acid levels and sensory 589 quality of lamb meat. J. Sci. Food Agric. 2016, 96, 1923-1933.

590 (36) Girard, M.; Dohme-Meier, F.; Wechsler, D.; Goy, D.; Kreuzer, M.; Bee, G. Ability of 3 591 tanniferous forage legumes to modify quality of milk and Gruyère-type cheese. J. Dairy Sci. 592 2016, 99, 205-220.

593 (37) Malisch, C. S.; Luscher, A.; Baert, N.; Engstrom, M. T.; Studer, B.; Fryganas, C.; Suter, 594 D.; Mueller-Harvey, I.; Salminen, J. P. Large variability of proanthocyanidin content and 595 596 composition in sainfoin (Onobrychis viciifolia). J. Agric. Food Chem. 2015, 63, 1023410242.

597

(38) Stringano, E.; Hayot Carbonero, C.; Smith, L. M.; Brown, R. H.; Mueller-Harvey, I. Proanthocyanidin diversity in the EU 'Healthyhay' sainfoin (Onobrychis viciifolia) 599 germplasm collection. Phytochemistry 2012, 77, 197-208.

600 (39) Hixson, J. L.; Bindon, K. A.; Smith, P. A. Evaluation of direct phloroglucinolysis and 601 colorimetric depolymerization assays and their applicability for determining condensed 602 tannins in grape marc. J. Agric. Food Chem. 2015, 63, 9954-9962.

603 (40) Brown, R. H.; Mueller-Harvey, I.; Zeller, W. E.; Reinhardt, L.; Stringano, E.; Gea, A.; Drake, C.; Ropiak, H. M.; Fryganas, C.; Ramsay, A.; Hardcastle, E. E. Facile purification of milligram to gram quantities of condensed tannins according to mean degree of polymerization and flavan-3-ol subunit composition. J. Agric. Food Chem. 2017, 65, 80726078082.

608 (41) Novobilský, A.; Mueller-Harvey, I.; Thamsborg, S. M. Condensed tannins act against 609 cattle nematodes. Vet. Parasitol. 2011, 182, 121-220. 
610 (42) Williams, A. R.; Fryganas, C.; Ramsay, A.; Mueller-Harvey, I.; Thamsborg, S. M.

611 Direct anthelmintic effects of condensed tannins from diverse plant sources against Ascaris

612 suum. PLoS One 2014, 9 (5), No. e97053, DOI: 10.1371/journal.pone.0097053.

613 (43) Watterson, J. J.; Butler, L. G. Occurrence of an unusual leucoanthocyanidin and absence 614 of proanthocyanidins in sorghum leaves. J. Agric. Food Chem. 1983, 31, 41-45.

615 (44) Newman, R.; Porter, L. Solid state ${ }^{13}$ C-NMR studies on condensed tannins. In Plant 616 Polyphenols, Hemingway, R.; Laks, P., Eds. Springer US: 1992; Vol. 59, pp 339-347.

617 (45) Preston, C. M.; Sayer, B. G. What's in a nutshell: An investigation of structure by 618 carbon-13 cross-polarization magic-angle spinning nuclear magnetic resonance spectroscopy. J. Agric. Food Chem. 1992, 40, 206-210.

(46) Schuerch, C. The solvent properties of liquids and their relation to the solubility, swelling, isolation and fractionation of lignin. J. Am. Chem. Soc. 1952, 74, 5061-5067. (47) Kim, H.; Ralph, J. Solution-state 2D NMR of ball-milled plant cell wall gels in DMSOd6/pyridine-d5. Org. Biomol. Chem. 2010, 8, 576-591. (48) Marais, J. P.; Mueller-Harvey, I.; Brandt, E. V.; Ferreira, D. Polyphenols, condensed tannins, and other natural products in Onobrychis viciifolia (sainfoin). J. Agric. Food Chem. 


\section{FIGURE CAPTIONS:}

Figure 1. A generic proanthocyanidin structure depicting flavan-3-ol subunits.

Figure 2. (A) Schematic representation of a proanthocyanidin structure consisting of a prodelphinidin subunit (top) and a procyanidin subunit (bottom), and (B) ${ }^{13}$ C CPMAS NMR spectra (black solid line) of purified prodelphinidin fraction from blackcurrant leaves (upper) and purified procyanidin fraction from Tilia flowers (lower). The assignment of the resonances is consistent with the labelled carbon positions of the proanthocyanidin structure including resolved terminal (4t) and internal (4i) carbons. The grey lines depict the corresponding dipolar dephased solid-state NMR spectra, which were optimized to detect only non-protonated carbons. The asterisks mark the spinning side-bands.

Figure 3. Comparison of ${ }^{13} \mathrm{C}$ CPMAS NMR spectra of milled plant tissues (black line), acetone/water crude extracts (green line) and purified proanthocyanidin fractions (blue line) from (A) blackcurrant leaves and (B) Tilia flowers. Black arrows depict the signals at 155 and $132 \mathrm{ppm}$. All spectra were normalized to the amplitude of the $155 \mathrm{ppm}$ signal to evaluate interferences from other plant components in the area of interest (160-120 ppm, highlighted in grey color).

Figure 4. Comparison of ${ }^{13} \mathrm{C}$ CPMAS NMR spectra of sainfoin plant (A) S3, (B) S1 and (C) S4 tissues. The insets show superimposed regions for comparison of the 155 and $145 \mathrm{ppm}$ proanthocyanidin signals and the 53 ppm lignin signal. 
Figure 5. (A) Comparison of the selected regions of ${ }^{13} \mathrm{C}$ CPMAS NMR spectra recorded for mixtures with nominal PC/PD values of 100/0, 70/30, 50/50, 30/70 and 0/100, prepared by mixing purified PA fractions (bottom) and milled plant tissues (top) of Tilia (PC-rich) and blackcurrant (PD-rich). The red arrows reflect the change in the $132 \mathrm{ppm}$ signal intensity as function of the nominal PC/PD value and a small change in chemical shift. The increase in the color intensity of lines (light grey to black) denotes the increase in the PC/PD value. The black arrows depict other signals that also reflect spectral differences but are less useful due to signal overlaps. All signals were normalized to the amplitude of the signal at $155 \mathrm{ppm}$ (red dot). (B) The relation between the intensity ratio $\mathrm{I}_{132} / \mathrm{I}_{155}$ and nominal PC/PD values for the calibration mixtures of purified PA fractions and milled plant tissues. The dots denote the experimental points and the red lines show fitted linear dependence.

Figure 6. Fingerprint ${ }^{13} \mathrm{C}$ CPMAS NMR spectra from sainfoin (A) leaves and (B) stems. Both spectra were fitted using the sum of Gaussian shape lines and the result of the fit is superimposed on the original spectrum (red dotted lines). The grey lines below show Gaussian lines used to fit the corresponding region of the spectrum. The signals from this region were used to estimate $\mathrm{PA}$ content and $\mathrm{PC} / \mathrm{PD}$ ratios and are shown in blue. 
Table 1. Proanthocyanidin (PA) Contents and Procyanidin (PC) Contents within Purified PA Fraction Determined by ${ }^{13} \mathrm{C}$ CPMAS NMR, the HCl-Butanol-Acetone Assay and ThiolysisHPLC Analysis.

\begin{tabular}{|c|c|c|c|c|c|c|c|}
\hline \multirow{2}{*}{$\begin{array}{l}\text { Sainfoin } \\
\text { plant } \\
\text { tissue }\end{array}$} & \multirow[t]{2}{*}{ Accession } & \multicolumn{4}{|c|}{ PA (g/100 g of plant tissue) } & \multicolumn{2}{|c|}{$\begin{array}{c}\text { PC (mg/100 mg of } \\
\text { purified PA } \\
\text { fraction) }\end{array}$} \\
\hline & & NMR & $\begin{array}{c}\text { NMR } \\
(-25 \%)^{a}\end{array}$ & HCl-butanol & Thiolysis & NMR & Thiolysis \\
\hline S1 & Zeus & $16^{b}$ & 12 & $5.0^{c}$ & $1.5^{d}$ & $20^{b}$ & $23^{d}$ \\
\hline S2 & Zeus & 16 & 12 & 5.3 & 3.4 & 30 & 18 \\
\hline S3 & Cholderton & 21 & 16 & 8.8 & 10.0 & 50 & 19 \\
\hline S4 & Hampshire & 14 & 10 & 7.1 & 5.2 & 30 & 19 \\
\hline S5 & Ambra & 18 & 14 & $n t^{d}$ & 5.2 & 30 & 19 \\
\hline S6 & Zeus & 15 & 11 & 4.3 & 1.7 & 10 & 18 \\
\hline S7 & Perly & 14 & 11 & 5.1 & 0.5 & 20 & 18 \\
\hline $\mathrm{S} 8^{e}$ & $\begin{array}{l}\text { Cotswold } \\
\text { Common }\end{array}$ & 19 & 14 & $n t$ & 4.2 & 20 & 19 \\
\hline
\end{tabular}

${ }^{a}$ Correction for lignin interference; ${ }^{b}$ experimental error was $\pm 8 \mathrm{~g} / 100 \mathrm{~g}$ of plant tissue for the PA content, and $\pm 16 \mathrm{mg}$ PCs $/ 100 \mathrm{mg}$ of purified PA fraction for the PC content within purified PA fraction; ${ }^{c}$ experimental error was $\pm 0.5 \mathrm{~g} / 100 \mathrm{~g}$ of plant tissue for the PA content; ${ }^{d}$ experimental error was $\pm 0.6 \mathrm{~g} / 100 \mathrm{~g}$ of plant tissue for the PA content, and $\pm 5 \mathrm{mg} \mathrm{PCs} / 100$ mg of purified PA fraction for the PC content within purified PA fraction; ${ }^{d} n t:$ not tested; ${ }^{e}$ sample S8 was analyzed only once. 


\section{Figure 1.}

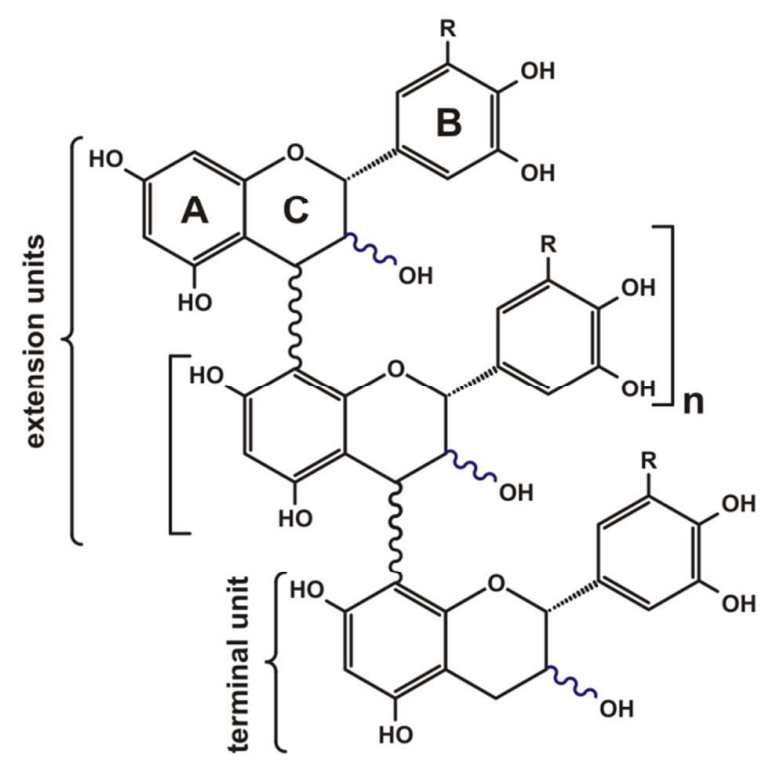

$\mathbf{R}=\mathbf{H}$, catechin or epicatechin are in procyanidins

$\mathbf{R}=\mathrm{OH}$, gallocatechin or epigallocatechin are in prodelphinidins

$\zeta=$...umun a cis-flavan-3-ol

$\xi=$ a trans-flavan-3-ol 


\section{Figure 2.}

A.

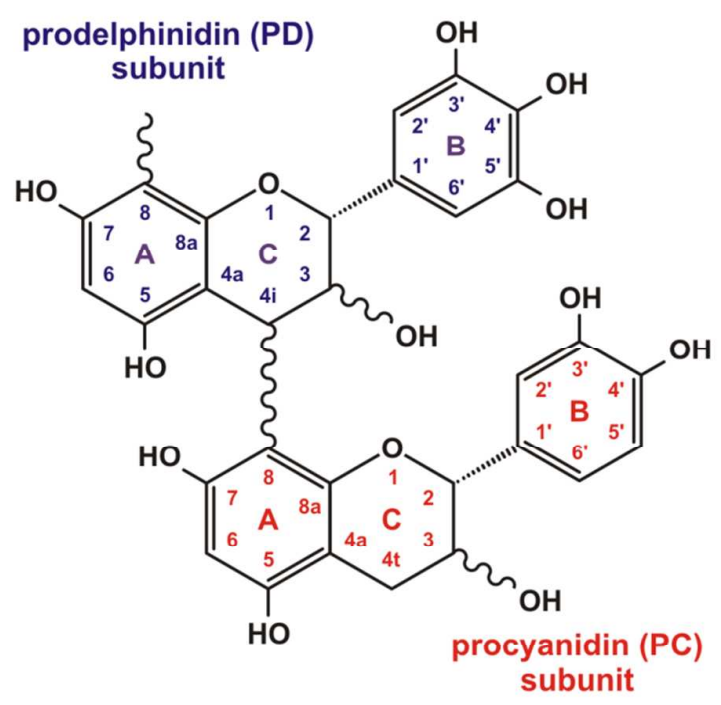

B. $5,7,8 \mathrm{a}$
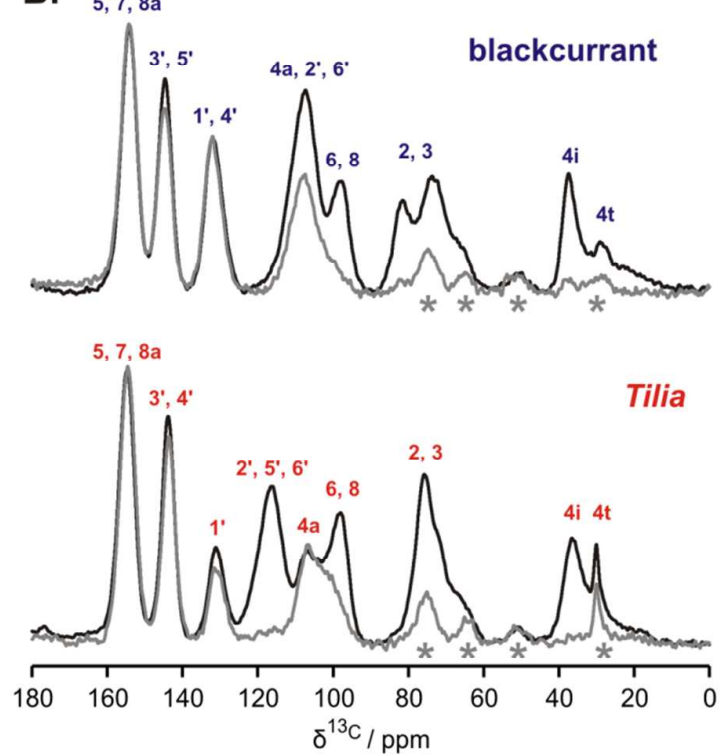
Figure 3.

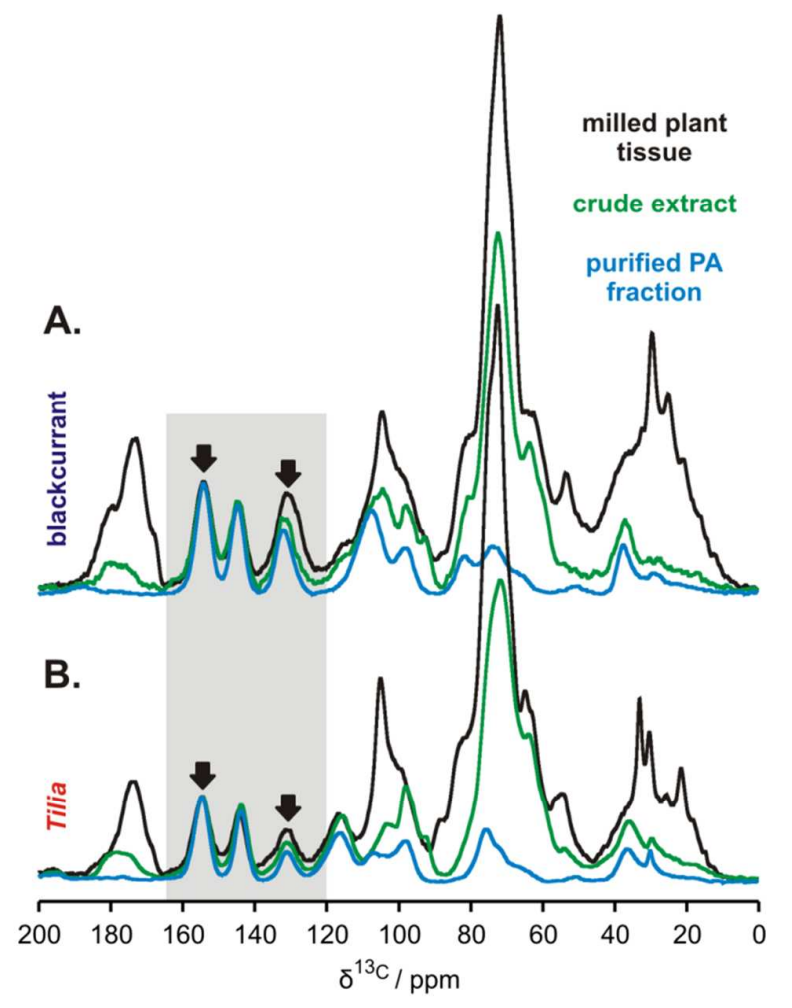




\section{Figure 4.}

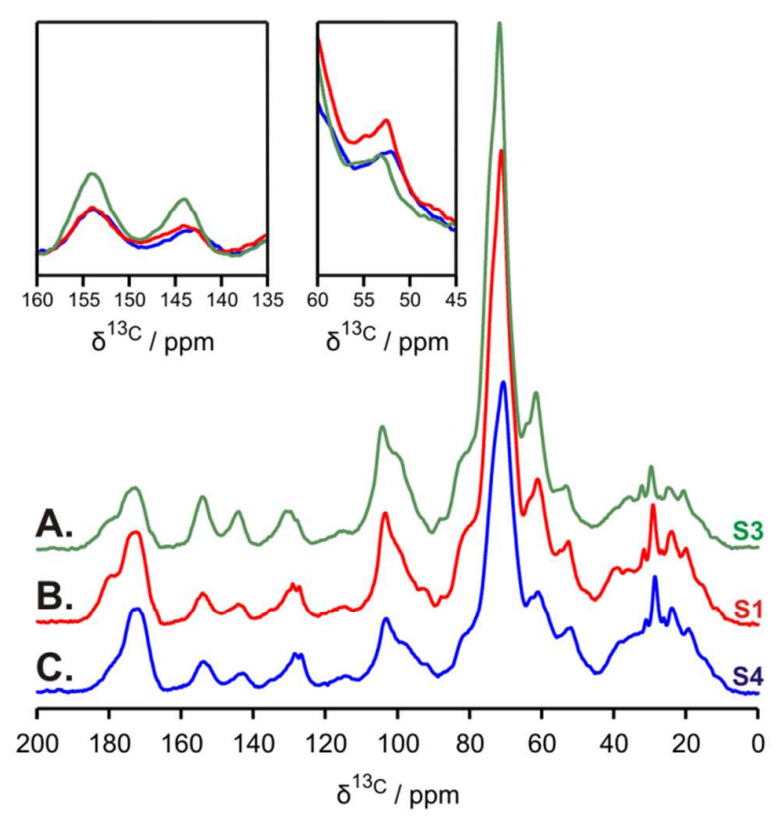




\section{Figure 5.}

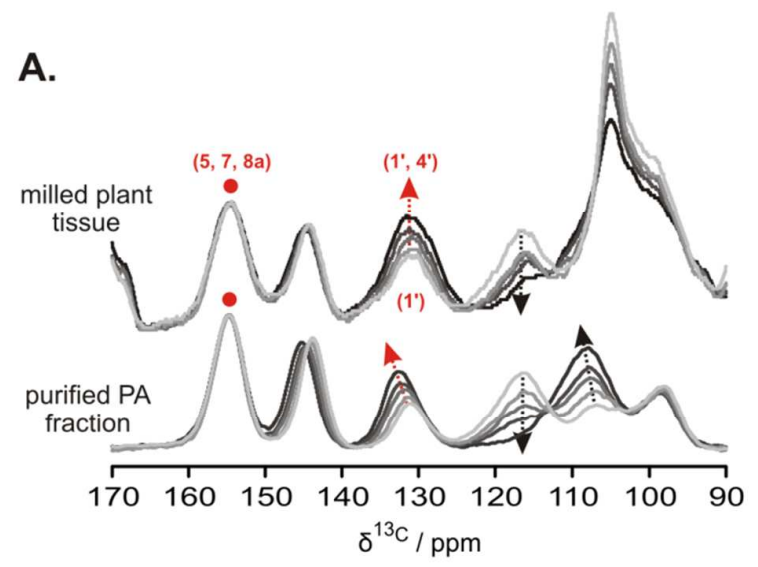

B. $\stackrel{P C \text { content within total } P A \text { increases }}{\longleftrightarrow}$

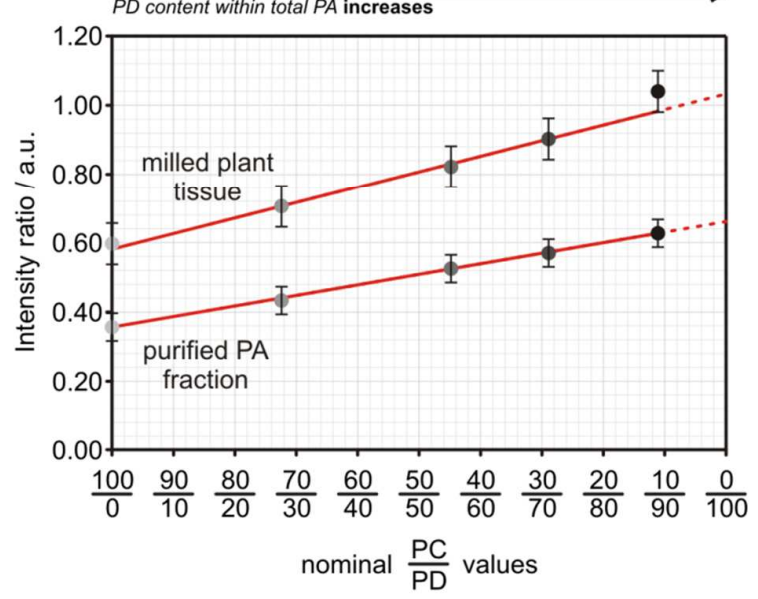




\section{Figure 6.}

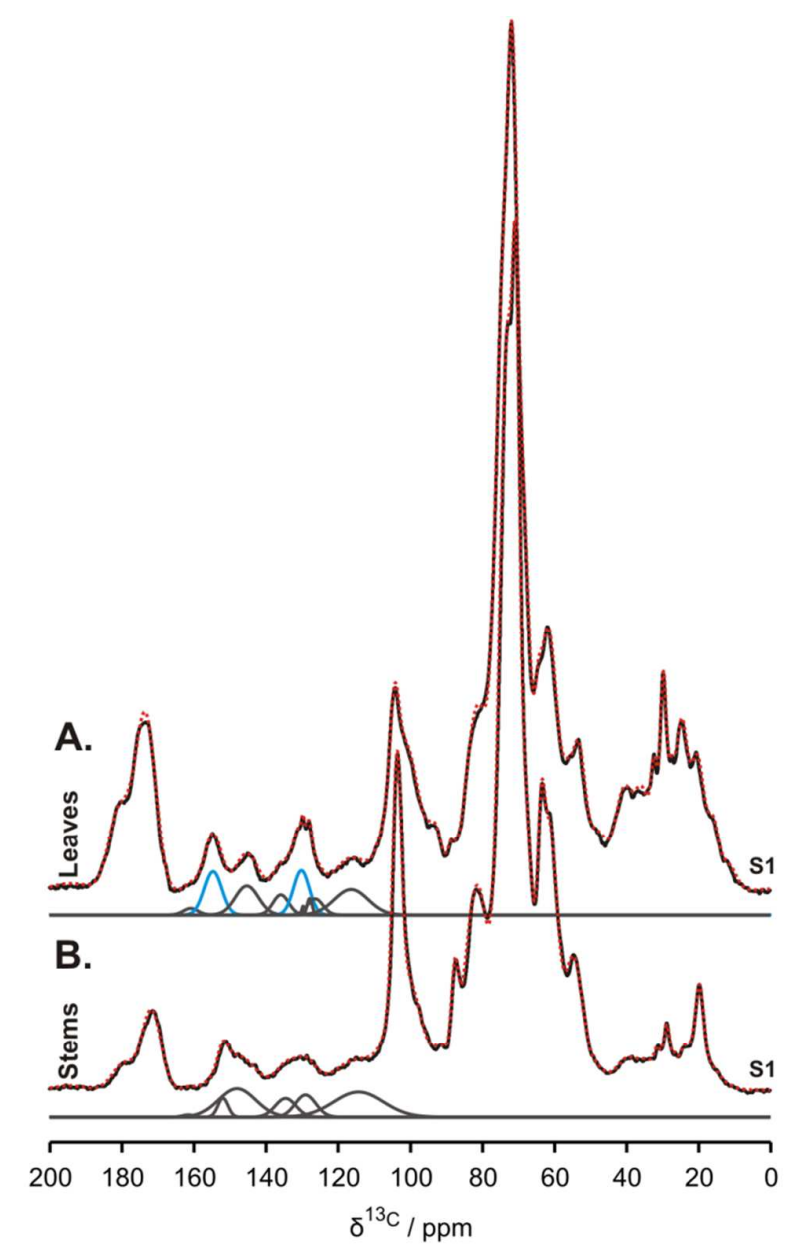




\section{GRAPHIC FOR TABLE OF CONTENTS:}

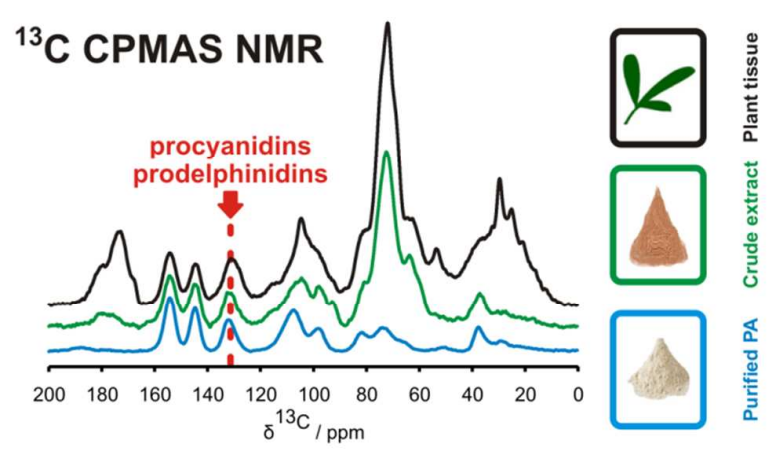

